\title{
Wildlife massacres in Sudan
}

\author{
J. L. Cloudsley-Thompson
}

While Saudi Arabia has recognized the dangers of uncontrolled hunting and has introduced conservation measures in its own territory, prominent members of that kingdom are killing large numbers of game, including endangered species, in neighbouring countries. In this report the author presents evidence of the devastation caused by Saudi hunters in the Sudan. While the latter country has outlawed hunting, enforcing the law against Saudi nationals is fraught with difficulties.

During a recent visit to Khartoum (March 1992) I took the opportunity to look round the Zoological Gardens, which I had not entered for many years. While inspecting the roan antelope Hippotragus equinus paddock, I was approached by one of the staff who explained to me, in Arabic, that the adult female was pregnant and that the smaller of the two males was her offspring. He said that roan were extremely common around Malakal, so I asked about the situation in Dinder National Park (Happold, 1966; Cloudsley-Thompson, 1973). He replied that, in that region, they had nearly all been shot and eaten by members of the local population, adding that the prisons were completely filled with transgressors who had been apprehended!

That an alarming drop in numbers of game had occurred in recent years was confirmed by Dr Eisa M. Abdellatif, of the Department of Zoology, University of Khartoum, who added that an additional cause had been the construction of the Rahad canal conducting water from the Roseires reservoir to agricultural land to the north-east. (I well remember, nearly 30 years ago, arguing with an FAO expert that migrating game would never cross the canal, even if bridges were constructed for their benefit and, moreover, if any did, that is just where they would be ambushed by poachers.)

Apparently the unfinished Jonglei canal bypassing the Sudd has, likewise, proved an insuperable obstacle to migration. The situation in the Nimule and Southern (Bahr el-
Gazal) National Parks, is at present, unknown.

Eisa Abdellatif also gave me a copy of Sudan Environmental Studies, the Newsletter of the Institute of Environmental Studies, University of Khartoum (dated April, 1989) containing an account (by Dr Mutasim B. Nimir, Director of the Wildlife Research Centre) of wildlife massacres in the Sudan by citizens of the Kingdom of Saudi Arabia. It is with permission that I have made the following abstracts from that article:

1. In 1984 the Saudi Minister of Public Works was caught poaching in Kordofan (Figure 1). $\mathrm{He}$ was chased by the senior Wildlife Conservation Forces (WCF) officer of Kordofan, but managed to escape and was not arrested. In his deserted camp sites were found remains of dozens of gazelles. He continued poaching in Darfur whence he was permitted to take home illegally captured ostriches and gazelles.

2. In 1985 a Saudi sheikh was arrested while poaching Nubian ibex in the Erkowit sanctuary. The State security authorities intervened and not only released the sheikh but arrested, for a short while, the game officer in charge.

3. In 1985 another Saudi prince was reported to have killed 120 gazelles in Kwamatet in the Red Sea province.

4. In December 1986 a Saudi prince, accompanied by a party of 30 other persons using 19 vehicles and two fuel tankers, was found poaching $200 \mathrm{~km}$ south of Sinkat. When his camp was searched 50 gazelles and five bustard carcasses were found. The prince was 


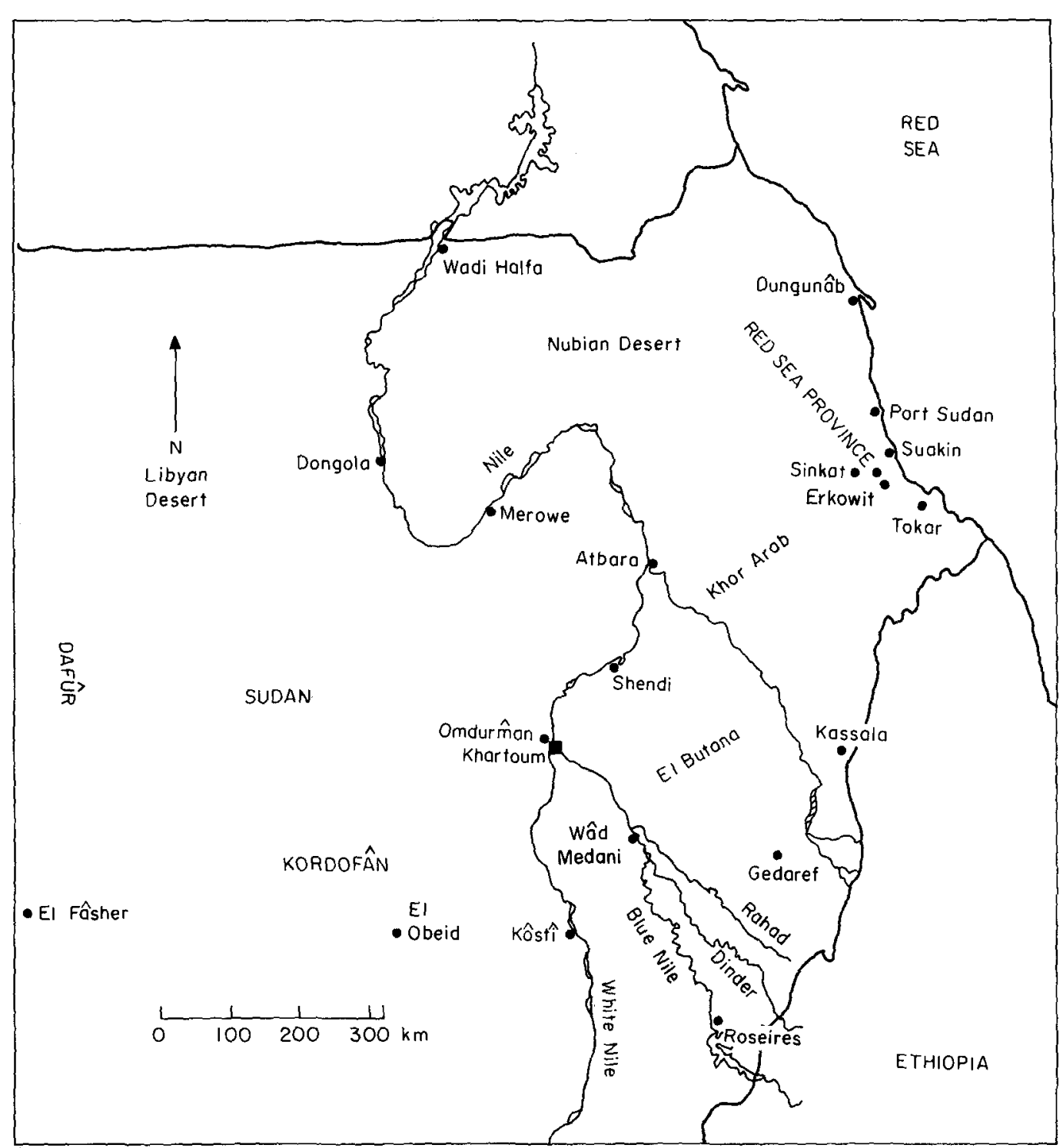

Figure 1. Map of Sudan showing locations of places mentioned in text.

arrested but the Governor of the Eastern Region ordered his release, returned all the carcasses held by the game officer, and allowed him to extend his poaching expedition for another month.

5. In 1987 a high-ranking Saudi prince killed 300 dorcas gazelles (Gazella dorcas, classified as Vulnerable by IUCN [1990]) and 103 bustards west of Omdurman and collected several live gazelles and ostriches. This massacre triggered a law case against the game officers concerned, who demanded an investigation at WCF headquarters.

6. In December 1987, a fourth Saudi prince was found to have killed 64 dorcas gazelles, including 13 pregnant females, near Khor Shah, $160 \mathrm{~km}$ from Port Sudan.

7. In April 1988 another high-ranking Saudi prince was reported to have shot 18 gazelles in Khor Arab, 22 in Khor Tamatamba, and 63 at a third site.

In all these cases, the prince or sheik con- 
cerned was accompanied by guards and followers ranging in numbers between 30 and 90 , using from 15 to 40 vehicles including refrigerator lorries, and equipped with large numbers of modern weapons and unlimited supplies of ammunition. In many cases, animals were chased and shot by automatic rifles from moving vehicles. At night, spotlights were used.

Numerous cases of the illegal export of live gazelles and other protected species are cited in the document from which I am quoting.

Despite a ban on all hunting imposed in January 1989, the massacre has continued. One Saudi prince and his retinue poached dorcas gazelles from Omdurman to western Darfur during February and March of that year. The group consisted of 97 people with 34 vehicles and was reported to have killed an average of 20 gazelles daily. Over a period of 83 days, 1660 dorcas gazelles and 3000 bustard were killed, and two dama gazelles Gazella dama (classified as Endangered [IUCN, 1990]) were captured.

The Saudi Government has long recognized the dangers of uncontrolled hunting of that country's own wildlife. To prevent this, the Saudi National Commission for Wildlife Conservation and Development (NCWCD) was established some years ago and the law is to some extent enforced (Thouless, 1991), at least as far as expatriates are concerned. The article in Sudan Environment takes the form of a message to the government and people of Saudi Arabia begging them to respect the laws of the Sudan.

It is very much to be hoped that the present Sudanese Government will be able to eliminate the corruption that characterized the preceding one, and prevent future massacres like those that have occurred during the last decade (Newby, 1990). Law enforcement cannot take place without improving the facilities and manpower of the WCF. However, it is difficult to see how this can be achieved during the present economic crisis while the country is so dependent upon aid from Saudi Arabia and while there is such a close relationship between the Saudi Government and royal family.

\section{References}

Cloudsley-Thompson, J.L. 1973. Developments in the Sudan Parks. Oryx, 12, 49-52.

Happold, D.C.D. 1966. The future for wildlife in the Sudan. Oryx, 8, 360-73.

IUCN, 1990. 1990 IUCN Red List of Threatened Animals. IUCN, Gland, Switzerland and Cambridge, UK.

Newby, J.E. 1990. The slaughter of Sahelian wildlife by Arab royalty. Oryx, 24, 6-8.

Thouless, C. 1991. Conservation in Saudi Arabia. Oryx, 25, 222-228.

J. L. Cloudsley-Thompson, Department of Biology, Medawar Building, University College London, Gower Street, London WC1E 6BT, UK. 